\title{
ASSEXUALIDADE EM SERIADOS TELEVISIVOS: UMA ANÁLISE SÓCIO-HISTÓRICA
}

\author{
ASEXUALITY ON TV SHOWS: A SOCIO-HISTORICAL ANALYSIS
}
Maria Laura Barros da Rocha1, Camila dos Anjos Falcão², Alana Madeiro de Melo Barboza $^{3}$ e Luciano Domingues Bueno ${ }^{4}$

1 Universidade Federal de Alagoas, Programa de Pós-graduação em Psicologia, Brasil, e-mail: laurabarrosrocha@gmail.com, ORCID: https://orcid.org/0000-0001-8857-4591.

2 Universidade Federal de Alagoas, Programa de Pós-graduação em Psicologia, Brasil, e-mail: camila.danjos@gmail.com, ORCID: https://orcid.org/0000-0001-8157-9832

3 Universidade Federal de Alagoas, Programa de Pós-graduação em Psicologia, Brasil, e-mail: madeiro.alana@gmail.com, ORCID: https://orcid.org/0000-0001-5951-141X

4 Universidade Federal de Alagoas, Programa de Pós-graduação em Psicologia, Brasil, e-mail: lucianodbueno@gmail.com, ORCID: https://orcid.org/0000-0001-7861-7092

A R T I C L E I N F O
Article history:
Received 2020-06-01
Accepted 2020-11-30
Available online 2020-11-30

RESUMO. Os seriados televisivos têm ocupado destaque na produção cultural na contemporaneidade. Utilizá-los como recurso de investigação científica visa construir um percurso metodológico capaz de subsidiar a análise sócio-histórica de aspectos psicossociais materializados e divulgados massivamente por esse canal de produção cultural. Sua interface com os estudos de gênero e sexualidade busca construir diálogos que viabilizem avanço de viés crítico na proposição de conceitos acerca de como a assexualidade é apresentada nesses produtos. Para isso, desenvolveuse um estudo descritivo-interpretativo, a partir da base online Internet Movie Database (IMDb). Na base de dados, os títulos "Better Half" da série House M.D. e "The Laws of Gods and Men" de Game of Thrones foram identificados como potencializadores da discussão da assexualidade. A partir dos episódios investigados foi possível aferir a assexualidade nos seguintes contextos: tratada como fenômeno desviante e patologizado; como aspecto pouco representado nos seriados; ou como parte de possibilidade de ser e existir no mundo. Por fim, os seriados são capazes de dar visibilidade a categoria assexualidade e também evidenciam a necessidade de construção de perspectivas de sexualidade mais inclusivas e menos norteadas por ideais hegemônicos, calcados na patologização e invisibilização.

ABSTRACT. TV shows have been prominent in contemporary cultural production. Using them as a
resource for scientific research aims to build a methodological path capable of supporting the socio-
historical analysis of psychosocial aspects materialized and massively disseminated by this culture
production channel. Its interface with gender and sexuality studies seeks to build dialogues that make
it possible to advance a critical bias in proposing concepts about how asexuality is presented in these
products. For this, a descriptive-interpretative study was developed, based on the online Internet
Movie Database (IMDb). In the database, the titles "Better Half" from the TV show House M.D. and
"The Laws of Gods and Men" from Game of Thrones, were identified as potentiators of the discussion
of asexuality. From the investigated episodes, it was possible to assess asexuality in the following
contexts: treated as a deviant and pathologized phenomenon; as an aspect little represented in the TV 
shows; or as part of the possibility of being and existing in the world. Finally, the TV shows are able to give visibility to the asexuality category and also demonstrate the need to build more inclusive perspectives of sexuality and less guided by hegemonic ideals, based on pathologization and invisibilization.

\section{Introdução}

A reflexão acerca da arte e das suas potencialidades não é uma preocupação recente na Psicologia. O autor Bielorrusso, Lev Semionovich Vigotski escreveu Psicologia da Arte (2001) para responder e incitar alguns questionamentos acerca desta relação possível entre Psicologia e a arte. A produção artística e cultural não é neutra e precisa ser estudada em seu contexto histórico e político. Isto é, as produções artísticas permitem o acesso e compartilhamento de sistemas simbólicos e culturais (VIGOTSKI, 1999; BARROCO; SUPERTI, 2014).

O grupo de pesquisa "Epistemologia e Ciência Psicológica", vinculado à Universidade Federal de Alagoas, têm realizado investigações buscando ampliar os horizontes acerca das da relação da arte com a com a sociedade, do o processo criativo humano e da potencialidade de análises psicossociais da ficção (FALCÃO et al., 2019; OLIVEIRA et al., 2019; OLIVEIRA; MIURA, 2019; ROCHA et al., 2019; SILVA; OLIVEIRA, 2013; SILVA; OLIVEIRA, 2014).

Por considerar a arte como concentração de vida e dos processos biológicos e sociais do sujeito na sociedade (VIGOTSKI, 2001), este artigo direciona-se no caminho de produzir interrogações acerca das possíveis concentrações psicossociais e de vida em personagens de obras artísticas, em especial as significações possíveis da assexualidade em seriados televisivos. Para tanto, intenciona responder aos seguintes questionamentos: quais conceitos e significações podem ser formulados acerca da assexualidade, de maneira crítica, a partir dos aspectos materializados em personagens de seriados?

Dentro da perspectiva Sócio-histórica em Psicologia as produções culturais ganham destaque como formas de objetivação de aspectos psicossociais de determinada realidade histórica (VIGOTSKI, 1999; 2009; WEDEKIN; ZANELLA, 2013; WEDEKIN, 2015). Na interface com as discussões advindas dos estudos de gênero, busca-se refletir quais configurações psicossociais estão objetivadas na videografia estudada e quais avanços metodológicos são possíveis na utilização deste tipo de produção como recurso investigativo. Como produto artístico, as séries podem ser compreendidas como artefatos culturais mediadores entre o indivíduo e o gênero humano (VIGOTSKI, 1999; 2001). 
Desse modo, este estudo objetivou o mapeamento de personagens assexuais na base Internet Movie Database (IMDb) e a reflexão crítica acerca da assexualidade em narrativas serializadas, bem como suas possíveis repercussões no imaginário social acerca desta orientação sexual.

\section{Fundamentação teórica}

A assexualidade é definida, em linhas gerais, por uma ausência de atração sexual por outras pessoas, independente do gênero (BEZERRA, 2015; BRIGEIRO, 2013). Assim como outras orientações sexuais, ela é uma categoria definida em um processo auto identificatório. Desse modo, por conta de um lugar de invisibilidade social que a assexualidade ocupa, é possível que os dados quantitativos que indicam uma população de 7\% mulheres e 2,5\% homens assexuais (FREITAS, 2017; LEMOS, 2018; VERRUMO, 2019) não correspondam ao número real, mas sim àquelas pessoas que tiveram acesso ao conceito e a linguagem para definir sua experiência nas palavras usadas pelos pesquisadores.

A invisibilidade social da assexualidade se fortalece através de mecanismos que perpetuam a atração sexual como uma característica humana inata (MOLLET; LACKMAN, 2020). Em seu estudo com estudantes canadenses, Maclnnis e Hodson (2012, p. 725, tradução nossa) apontam que assexuais são "um alvo social avaliado mais negativamente, vistos como menos humanos e menos valorizados como parceiros de contato, em relação a heterossexuais e outros minorias".

As categorias como homossexualidade, heterossexualidade e bissexualidade são construídas a partir de um direcionamento da atração sexual (ao mesmo sexo, ao oposto ou a ambos), em uma lógica na qual a sexualidade é determinada pelo direcionamento ao outro. Todavia, a assexualidade, por caracterizar-se pela ausência desse direcionamento, fica impossibilitada de ocupar um espaço dentro do discurso hegemônico e allonormativo, que procura justificativas em discursos biomédicos patologizantes ou que a colocam em um lugar de inexistência.

Segundo Mollet e Lackman (2020), Allonormatividade é uma palavra derivada de allosexual, que referencia a forma de socialização que perpetua a normatividade da atração sexual. O uso de allosexual, uma palavra cunhada pela Comunidade Assexual para designar pessoas que não são assexuais, desloca o estigma ao criar uma nomenclatura que fornece "uma alternativa para a justaposição de que pessoas ou são normais (isto é, sexuais), ou são diferentes (isto é, assexual)" (MOLLET; LACKMAN, 2020, p. 82, tradução nossa). 
Quando esse não lugar, caracterizado pelo não direcionamento de interesse sexual à outra pessoa, que a assexualidade ocupa é encarnado em um roteiro ou personagem, a mídia faz com que ele seja visível. Desse modo, voltar o olhar de análise para a representação da assexualidade nas séries, parte da compreensão de que este é um meio de grande alcance ao público que participa na construção e disseminação de discursos acerca dos temas sobre os quais versam, além de ter o poder de produzir efeitos no imaginário social. Justificativa que ganha relevância por conta da importância que os recursos imagéticos têm alcançado na contemporaneidade e sua potencialidade nas pesquisas qualitativas (BAUER; GASKELL, 2002; BUENO et al., 2017). Siegfried Kracauer, ainda "defende que os filmes produzidos para, e consumidos por uma nação, permitem uma boa percepção das profundas disposições psicológicas" (apud BAUER; GASKELL, 2002 p.138). Aspecto que nos permite compreender que as representações da assexualidade no cinema, bem como nos seriados, pode subsidiar apreensão de aspectos psicossociais objetivados nessas produções imagéticas.

Dessa forma, foram realizados estudos investigativos da construção do conceito de assexualidade (BARBOZA et al., no prelo), buscando compreender não só como ele estava sendo utilizado academicamente, mas também o que estava sendo produzido acerca daquilo que poderia ser característico de uma experiência assexual. Os dados apontaram para a dificuldade em encontrar produções sobre a temática no cenário brasileiro apesar de o país ser um dos que possuem o maior número de assexuais autodeclarados (FREITAS, 2017; LEMOS, 2018; VERRUMO, 2019). Assim, materializa-se a relevância da presente discussão, bem como a escolha metodológica de buscar em elementos culturais (seriados) referenciais sócio-históricos que possam produzir diálogos com o campo teórico e subsidiar referenciais alternativos, frente à escassez de discussões sobre aspectos relacionados à assexualidade (BARBOZA et al, no prelo).

São necessários alguns esclarecimentos entre categorias comumente confundidas no imaginário social e tratadas como sinônimos: celibato e assexualidade. Este equívoco se deve, principalmente, a uma conflação entre orientação e comportamento sexual. A orientação sexual corresponde ao direcionamento da atração ou desejo sexual para pessoas do mesmo gênero (homossexualidade), do gênero oposto (heterossexualidade), de ambos os gêneros (bissexualidade) ou, no caso da assexualidade, o não direcionamento da atração para outras pessoas.

Em contraponto, comportamento sexual concerne às práticas sexuais ou a sua abdicação, ou seja, é da ordem de uma escolha, enquanto que a orientação corresponde a algo involuntário. Por ser uma conduta escolhida pelo sujeito, ela não precisa necessariamente corresponder à sua orientação sexual, de modo que alguns assexuais, 
apesar de não sentirem atração sexual para com seus parceiros românticos, engajam em práticas sexuais, por diversos motivos, como por exemplo, a manutenção de um relacionamento com alguém que não é assexual; da mesma forma, alguém heterossexual, pode optar, por conta de suas crenças religiosas, abdicar da prática sexual.

Outra distinção necessária é entre assexuado/a e assexual. O primeiro termo está relacionado a estudos da biologia sobre reprodução assexuada, em que os organismos se reproduzem sem troca de material genético, como é o caso das bactérias. A necessidade de discernimento entre os dois termos apresenta-se quando comparado às outras orientações sexuais, as quais terminam com o sufixo "sexual" e não "sexuado". Isto é, se dizemos "heterossexual" e não "heterossexuado", porque utilizaríamos "assexuado" ao invés de "assexual'? Questões que são levantadas para sinalizar que até mesmo em dimensões basilares, como o campo da linguagem, há uma distinção da assexualidade em relação a outras configurações sexuais.

\section{Método}

O estudo descritivo-interpretativo da assexualidade em séries de televisão ocorreu por meio de coordenadas metodológicas desenvolvidas no grupo de pesquisa Epistemologia e Ciência Psicológica (OLIVEIRA et al., 2017; OLIVEIRA et al., 2019) e adaptadas para corresponder de forma mais integral aos objetivos traçados: exploração, cruzamento, refinamento, descrição e interpretação.

\subsection{Coleta de dados}

A etapa de exploração diz respeito aos procedimentos de escolha do banco de dados, dos descritores e consolidação da amostra (OLIVEIRA et al., 2017). A base online Internet Movie Database (IMDb) foi escolhida por fornecer informações acerca de séries e filmes, além de permitir a consulta através de palavras-chaves (keywords) e a utilização de filtros de pesquisa que auxiliam no refinamento da amostra. A potencialidade dessa plataforma como base de dados para mapeamento e análise psicossocial foi explorada em estudo anterior do grupo de pesquisa (OLIVEIRA et al., 2019).

$\mathrm{Na}$ consulta ao banco foram inseridos, de forma individual, os descritores assexual e asexuality na base online que indicaram 60 títulos. Com o filtro "TV Episode", o quantitativo diminuiu para oito títulos. A utilização dos termos em inglês deve-se ao fato de essa ser a língua utilizada pela plataforma, dessa forma, estas são as palavras-chave reconhecidas pelo banco. 


\subsection{Armazenamento e Tratamentos dos dados}

A fim de detectar possíveis duplicações, realizou-se a etapa de cruzamento, que corresponde à comparação entre os títulos indicados para a exclusão de material repetitivo. Ao final do cruzamento não foram encontradas duplicações no quantitativo, de modo que as páginas online referentes à pesquisa foram salvas em PDF e armazenadas no Google drive. As informações relevantes para a pesquisa foram sistematizadas em uma planilha Excel, como descrito na Figura 1.

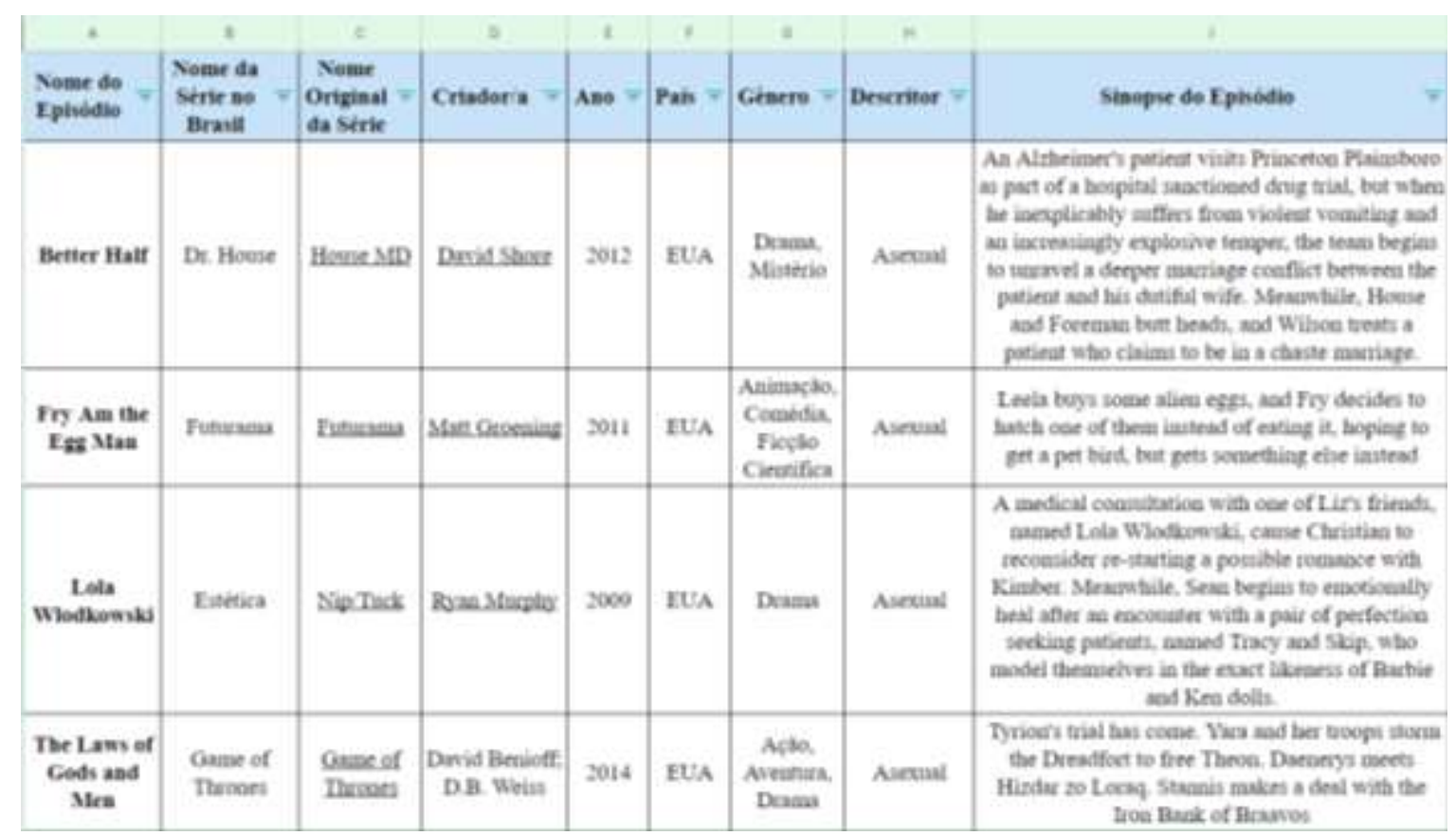

Figura 1 - Recorte da tabela de sistematização das informações Fonte: Autores (2019).

Em seguida, para consolidar a qualificação da amostra realizou-se o refinamento, o primeiro momento de tratamento de dados, que consiste na análise de quais materiais se relacionam com o objetivo da pesquisa (OLIVEIRA et al., 2017). Esta etapa desenvolveu-se através de dois momentos, inicialmente foram identificados apenas os títulos de ficção e, subsequentemente, os documentários foram excluídos da amostra. Já no segundo movimento refinatório, através da visualização dos episódios, foram identificados àqueles que tratavam de alguma forma da assexualidade ligada à experiência humana desta, de modo que foram excluídos os títulos que tratavam de reprodução assexuada e modificações corporais para a construção de um corpo "assexuado".

Com o material indicado ao final do refinamento, deu-se início a identificação das 
cenas e diálogos relevantes para o objetivo proposto. Por fim, realizou-se um processo descritivo e analítico através da interpretação do conteúdo das cenas. Ressalta-se que a interpretação realizada é apenas uma das várias possibilidades de compreensão, de modo que não representa a verdade absoluta acerca dos fatos (VIGOTSKI, 1999; VIGOTSKI, 2001).

\section{Resultados}

Dentre os 60 episódios indicados pela plataforma na consulta inicial, 52 não se tratavam de episódio de séries de TV, quatro não se tratavam de ficção e dois não estavam relacionados à orientação sexual ("Fry Am the Egg Man" de "Futurama" e "Lola Wlodkowski" de "Nip/Tuck"), de modo que durante o refinamento eles foram retirados da amostra.

Os títulos indicados pela plataforma IMDb nos permite perceber que, mesmo em uma plataforma que possui 4.044.529 títulos de episódios cadastrados (IMDB, 2019), a assexualidade aparece relativamente ausente das telas, com apenas um episódio que utiliza palavra assexualidade (como orientação sexual) entre os resultados indicados pelo banco.

Apesar de não corresponder aos objetivos traçados neste estudo (e de o episódio ter ficado de fora do corpus final da pesquisa), vale a pena descrever o contexto em que a palavra "assexual" aparece no episódio "Fry Am the Egg Man" (Ep. 22, 6a temporada) da série estadunidense Futurama, uma vez que este auxilia na exposição de discursos que se fazem presentes no imaginário social da assexualidade, ou seja, a ideia que humanos são seres sexuais e os assexuais são só podem ser aqueles que se multiplicam e produzem cópias de si mesmo.

Futurama é uma série de ficção científica onde criaturas diversas e aliens aparecem, de modo que a figura de Mr. Peppy, uma criatura capaz de reprodução assexual não é tão fora do escopo da série. Ressalta-se que em nenhum momento da narrativa serializada há qualquer invalidação da assexualidade como orientação sexual ou sua apresentação como orientação sexual, de modo que, ao contrário do que acontece em House M.D., que será explorado adiante, o episódio de Futurama não participa diretamente dos discursos problemáticos que tentam refutar a assexualidade como possibilidade da sexualidade humana. Entretanto, a posição de Mr. Peppy serve como ilustração daquilo que ainda continua presente no imaginário das pessoas como a única possibilidade de assexualidade: a biológica.

Considerando os objetivos, ao final do refinamento, a descrição e a análise voltou- 
se principalmente para a forma como a assexualidade é apresentada nos episódios "Better Half" da série "House MD" e "The Laws of Gods and Men" de Game of Thrones. O primeiro refere-se à discussão da temática da assexualidade, mais especificamente, a compreensão dos personagens acerca de sua inexistência, enquanto o segundo apresenta um personagem que apesar de não ter a sua sexualidade confirmada explicitamente no episódio, apresenta-se com características que ajudam a discutir a experiência assexual.

\subsection{A medicalização da assexualidade em House M.D.}

Em Better Half, nono episódio da oitava e última temporada da série norteamericana House M.D. (Dr. House, no Brasil), o telespectador é apresentado a uma paciente da clínica médica que durante a consulta com Dr. Wilson, melhor amigo de House (personagem titular da série) fala que é assexual e que não mantém relações sexuais com seu marido, que também é assexual. Tanto a paciente quanto o seu marido não tem nomes referenciados no episódio, apesar de que sejam creditados nomes dos personagens na página do IMDb. Neste artigo, optou-se por referenciar os personagens pela designação "Paciente" e "Marido", para manter a forma como os personagens foram retratados no episódio analisado e evidenciar a despersonalização que a ausência de um nome lhes confere.

Intrigado com a fala da Paciente sobre a ausência de uma vida sexual ativa em seu casamento, Wilson recorre a House, que em descrença aposta ser capaz de encontrar uma razão médica para a aparente assexualidade da paciente. Neste momento, o personagem House materializa, em sua fala, o que podemos identificar como uma visão hegemônica da sexualidade, na qual aquilo que não se adequa a tal matriz lógica é enxergado com desviante e patológico.

House acaba descobrindo que apesar de não haver nada fisiologicamente errado com a Paciente, o Marido possui um tumor cerebral que causa diminuição de libido. Isto é apresentado tanto por Wilson e House como a "causa" da sua falta de atração. Ao descobrir sobre o tumor e que o tratamento poderia "curá-lo" de sua condição, a Paciente desabafa que ela não é assexual, apenas havia dito isto por amor seu marido e por não querer que ele sofresse ao pensar que estaria privando ela de relações sexuais. Apesar de palavras como "assexualidade" e "assexual" aparecem com frequência no episódio, a sua existência é negada o tempo todo, seja por considerar que é impossível que alguém esteja vivo e não se interesse por sexo; ou por considerar que alguém que se diga assexual só pode estar mentindo ou necessitando que um médico a auxilie na busca de uma cura para algo que precisa estar errado com ela. Ou seja, a perspectiva da assexualidade como comportamento desviante é reforçada, uma vez que os dois casos do episódio são 
apresentados como equívocos (um causado por uma patologia e o outro por uma mentira).

Dentre os diálogos presentes no episódio nada ilustra melhor a visão perpetuada pelo episódio quanto à fala de Dr. House "As únicas [pessoas] que não querem fazer sexo estão doentes, mortas ou mentindo" (BETTER..., 2012, tradução nossa). Além de ilustrar um pensamento coletivo sobre a assexualidade presente no episódio, esta frase também serve para a condução de um final que apenas a reafirma.

Não há espaço para a assexualidade no mundo criado em Better Half, apenas para a negação da sua existência, uma vez que em nenhum momento somos apresentados a uma alternativa positiva de vivência da assexualidade, apenas a da Paciente e do Marido. Nesse sentido, o episódio participa da perpetuação e disseminação de preconceitos acerca desta orientação sexual, ecoando, seja de forma implícita ou explicitamente, a defesa da medicalização da assexualidade como alternativa para a "normalização" dos sujeitos percebidos narrativamente como sofredores de uma patologia. Afinal, reiterando as palavras quase proféticas de House, ao final do episódio um deles estava doente e a outra estava mentindo.

\section{1 É preciso dizer em voz alta para ser verdade?: o subtexto da assexualidade em Game of Thrones}

Game of Thrones é uma série baseada na série de livros As Crônicas de Gelo e Fogo (Song of Ice and Fire, no idioma original) de George R. R. Martin. Apesar de ser uma série que possui enredos sexualizados e ter uma abundância de cenas de nudez, a discussão de orientações sexuais só está presente em Game of Thrones de forma implícita. Enquanto é inegável que há uma discussão sobre sexualidade na série, não há uma nomeação explícita orientações sexuais no diálogo de nenhum dos personagens (HORNBY, 2019).

Desse modo, o fato da possível assexualidade de Varys não ser nomeada no episódio "The Laws of Gods and Men" (Ep. 6, 4 temporada), ou em qualquer outro que o antecedeu ou procedeu, não é algo fora do comum. Por ter como inspiração a era medieval, a qual George R. R. Martin adiciona elementos de fantasia como mágica e dragões, a sua visão da sexualidade parece seguir um tempo em que não se havia a necessidade ou prática de nomeação de uma sexualidade. Os personagens Loras e Renly, por exemplo, são homens que se apaixonam um pelo outro, mas não são denominados homossexuais porque essa palavra não está disponível no universo fictício do qual fazem parte, assim como ela não existia no mundo medieval (MILLS, 2015).

Portanto, apesar de ser uma leitura de algo que não é explicitado na narrativa do 
episódio, optou-se por manter "The Laws of Gods and Men" no quantitativo por ele expressar através do personagem Varys algo que, ainda que não nomeado, evoca uma experiência de assexualidade do personagem. Além disso, a presença do personagem em um mundo hipersexualizado como o de Game of Thrones, evidencia ainda mais a experiência de Varys que salta aos olhos como algo digno de nota.

O personagem Varys no início da série é eunuco e ocupa o cargo de Mestre dos Sussurros - um cargo de espionagem no Reino -, mas seu passado é retomado por ele em momentos pontuais, nos quais é revelado que ele costumava ser um escravo e foi castrado em sua juventude pelo seu mestre, um feiticeiro, em um ritual mágico. Outro aspecto importante de seu passado é retomado em "The Laws of Gods and Men" quando sua sexualidade é colocada em questão, pelo personagem Oberyn Martell, que curioso sobre as preferências de Varys, questiona por quem ele sentia desejo antes de sua castração:

Oberyn: Minha amante, Ellaria, Ihe acharia muito interessante. Você deveria ir ao bordel e conhecê-la. Trouxemos nosso próprio vinho - não o suor que eles servem aqui - e temos alguns garotos adoráveis, mas... Você gostava de garotos antes (de se tornar eunuco)? [Varys balança a cabeça negativamente] Sério? Garotas? Hummm... Espero que você não se ofenda quando digo que nunca teria imaginado.

Varys: De forma alguma... mas eu também nunca me interessei por garotas Oberyn: Em que, então?

Varys: Nada.

Oberyn: Todos se interessam por algo.

Varys: Eu não. Quando vejo o que o desejo faz com as pessoas - o que fez com esse país - eu fico feliz de não ter parte nisso. Além do mais, a ausência de desejo nos deixa livre para buscar... outras coisas. (THE..., 2014, tradução nossa).

Nesta cena, Oberyn e Varys aparecem como contrastes um do outro. A forma como Oberyn é hipersexual(izado) evidencia ainda mais o quanto Varys não é sexualizado pela narrativa. A confusão de Oberyn quanto à "falta de interesse" de Varys parte de suas experiências com seu próprio desejo, evidenciadas em "Breaker of Chains", terceiro episódio da mesma temporada, onde o personagem fala sobre não ter preferências entre homens e mulheres:

Olyvar: Você gosta de ambos da mesma forma? Garotos e garotas?

Oberyn: Isso te surpreende?

Olyvar: Todo mundo tem uma preferência.

Oberyn: Então, todo mundo está perdendo metade dos prazeres do mundo.

(BREAKER..., 2014, tradução nossa).

Apesar da confusão mostrada perante a uma informação nova para Oberyn, ele não parece desmerecer a forma como Varys se sente, ou mesmo tentar dissuadi-lo. Ao final da conversa, Oberyn parece acreditar em Varys e essa informação não parece invalidar o respeito que tem por ele. Nesse sentido, o episódio coloca dois pontos de vista em choque, duas pessoas diferentes, mas ao mesmo tempo não enquadra nenhum dos dois como errados ou anormais. 
Outro ponto importante é o fato de o personagem ser eunuco não é apontado como a causa de sua falta de atração (ou "interesse", nas palavras do personagem). A pergunta de Oberyn sobre se ele "gostava de garotos antes (de se tornar eunuco)?" (THE..., 2012, tradução nossa), é fraseada de forma a evidenciar que Oberyn acredita que o comportamento atual de Varys poderia ser explicado por sua castração, contudo, a resposta é sobre uma ausência de desejo antes mesmo deste acontecimento. Dessa forma, ao falar sobre como ele era antes da castração, Varys descreve sua sexualidade não como resultado de uma violência ou da perda de algo, mas como parte inerente de si mesmo.

\section{Considerações finais}

Reconhece-se que as séries são um meio digital com potencialidades de disseminação de discursos de elevado alcance de telespectadores de diversas idades. Apesar disso, percebeu-se que a representatividade da assexualidade aparece em momentos escassos e de formas problemáticas, por meio da sua negação a partir do discurso médico, ou sem a sua nomeação de forma clara.

Diante de uma sociedade ainda fortemente guiada pelo modelo allonormativo e pela hipersexualização, percebeu-se que o episódio Better Half não foge a esse modelo e, assim, corroborra com a invisibilidade e negação da existência da assexualidade como orientação sexual. Por outro lado, apesar da não nomeação explícita da assexualidade, o episódio de Game of Thrones apresenta uma construção do personagem Varys que não o coloca para ocupar o lugar de doente ou anormal. Entretanto, a falta do rótulo pode implicar no alcance menor do seu impacto na desconstrução de preconceitos fora da série, enquanto por usar o termo, o alcance de House M.D. em perpetuar certos estereótipos pode acabar sendo mais vasto.

Nesse sentido, a análise sócio-histórica de enredos serializados relacionados à assexualidade apresenta importância singular ao carregar a discussão sobre a temática para o meio científico e questionar a forma como mídias de comunicação em massa lidam com a representatividade, ou a ausência representação, de comunidades constantemente patologizadas e invisibilizadas.

\section{Agradecimentos}

Agradecemos à Coordenação de Aperfeiçoamento de Pessoal de Nível Superior (CAPES) por bolsas de mestrado e ao grupo de pesquisa "Epistemologia e Ciência Psicológica" que possibilitou encontros que resultaram no trabalho e a retomada do mesmo para ampliação 
daquilo que havia sido apresentado no IV Desfazendo Gênero e no VIII CONINTER. Encontros que sinalizam potencialidades para retomadas futuras da discussão e que podem suscitar outros trabalhos.

\section{REFERÊNCIAS}

BARBOZA, A. M. M. et al. Metassíntese do conceito de Assexualidade. Ebook do IV Desfazendo Gênero, no prelo.

BARROCO, S.M.S.; SUPERTI, T. Vigotski e o estudo da Psicologia da Arte: contribuições para o desenvolvimento humano. Psicologia \& Sociedade, v. 26, n. 2. P. 22-32, 2014.

BAUER, M.; GASKELL, G.(orgs). Pesquisa qualitativa com texto, imagem e som: um manual prático Petrópolis: Editora Vozes. 2002.

BETTER half (Temporada 8, ep. 9). House MD [Seriado]. Direção: Greg Yaitanes. Produção: Elisabeth James, Gerrit Van Der Meer. EUA: Universal Television, 2012. (44 min.), son., color.

BEZERRA, P. V. Os avessos do excesso. Assis, 2015. Tese (Doutorado em Psicologia) Universidade do Estado de São Paulo.

BREAKER of chains (Temporada 4, ep. 3). Game of Thrones [Seriado]. Direção: Alex Graves. Produção: David Benioff, D. B. Weiss. HBO, 2014. (57 min.), son., color.

BRIGEIRO, M. A emergência da assexualidade: notas sobre política sexual, ethos científico e o desinteresse pelo sexo. Sex., Salud Soc. (Rio J.), Rio de Janeiro, n. 14, p. 253-283, Aug. 2013. Disponível em: <http://www.scielo.br/scielo.php?script=sci arttext\&pid=S1984$\underline{64872013000200012 \& \mathrm{lng}=\mathrm{en} \& \mathrm{nrm}=\mathrm{iso}}>$ >. Acesso em $07 \mathrm{Jul} 2019$.

BUENO, L. D. et al. Iconografia na investigação e intervenção de processos psicossociais. Revista De Psicologia, v.8, n.1, p. 99-108, 2017. Disponível em: <http://www.periodicos. ufc.br/psicologiaufc/article/view/18783> Acesso em 01 nov. 2019.

FALCÃO, C. A. et al. Assexualidade em seriados televisivos: uma análise Sócio-Histórica. Anais IV Desfazendo Gênero. Campina Grande: Editora Realize, 2019. Disponível em: https://editorarealize.com.br/revistas/desfazendo genero/trabalhos/TRABALHO EV129 MD 1 SA31 ID437 01112019232455.pdf. Acesso em: 01 jun. 2020.

FREITAS, H. Assexualidade: pouco discutida, mais comum do que se imagina. O Estado de S. Paulo. 2017. Disponível em: <https://emais.estadao.com.br/noticias/comportamento, assexualidade-pouco-discutida-mais-comum-do-que-se-imagina,70002028481> Acesso em: 30 out. 2019.

IMDB. IMDb Statistics. 2019. Disponível em:<https://www.imdb.com/pressroom/stats/> Acesso em: 01 nov. 2019.

LEMOS, V. Quem são os assexuais: relatos de brasileiros que não se interessam por sexo. BBC News Brasil, 2018. Disponível em: <https://www.bbc.com/portuguese/geral45634242> Acesso em 30 out. 2019.

HORNBY, S. M. Game of Thrones: dangerous world where LGBTQ characters die young or rot in jail. 2019. Disponível em <https://www.asianage.com/life/ morefeatures/240419/game-of-thrones-and-sexuality.html> Acesso em: 01 nov. 2019. 
MACINNIS, C. C.; HODSON, G. Intergroup bias toward "Group X": Evidence of prejudice, dehumanization, avoidance, and discrimination against asexuals. Group Processes \& Intergroup Relations, v. 15, n. 6, 2012, p. 725-743. https://doi.org/10.1177/13684302124 42419.

MILLS, R. Seeing Sodomy in the Middle Ages. Chicago: University of Chicago Press, 2015.

MOLLET, A. L.; LACKMAN, B. Asexual Student Invisibility and Erasure in Higher Education: "I Thought I Was The Only One". In ZAMANI-GALLAHER, E. M.; CHOUDHURI, D. D.; TAYLOR, J. L. (Eds.). Rethinking LGBTQIA students and collegiate contexts: Identity, Policies, and Campus Climate. New York: Routledge, 2020, p. 78-98.

OLIVEIRA, A. A. S. et al. A produção de conceitos e de métodos na pesquisa psicológica: contribuição da metassíntese ao conhecimento científico. In: Oliveira, A. A. S (Org.). Psicologia Sócio-Histórica e o contexto de desigualdade psicossocial: teoria, método e pesquisas. Maceió: EDUFAL, 2017, p. 71-86.

OLIVEIRA, A. A. S. et al. As infâncias e crianças na filmografia de dramas. Atas CIAIQ, v. 01, n. 01, 2019, p. 238-247. Disponível em:<https://proceedings.ciaiq.org/ index.php/CIAIQ2019/article/view/2082>. Acesso em: 01 jun. 2020.

OLIVEIRA, A. A. S.; MIURA, P. O. Artes e humanidades. Maceió: Edufal, 2019.

ROCHA, M. L. B. et al. Narrativas Invisíveis: reflexões acerca da representação da assexualidade em séries. Anais do VIII CONINTER. 2019. Disponível em: https://even3. blob.core.windows.net/processos/4c7840c1c0584fd4ac45.pdf. Acesso em: 01 jun. 2020.

VERRUMO, M. Eles não pensam naquilo. Superinteressante. 2016. Disponível em: $<$ https://super.abril.com.br/comportamento/eles-nao-pensam-naquilo/> Acesso em: 30 out. 2019 .

SILVA, A. L.; OLIVEIRA, A. A. S. Transexualidade e cinema: um estudo psicossocial Polêm!ca, v. 13, p. 1327-1334, 2014.

SILVA, A. L.; OLIVEIRA, A. A. S. Transexualidade/travestilidade na literatura brasileira: sentidos e significados. Arquivos brasileiros de Psicologia, Rio de Janeiro, v. 65, n. 2, 2013, p. 274-287.

VIGOTSKI, L. S. A formação social da mente: o desenvolvimento dos processos psicológicos superiores. São Paulo: Martin Fontes, 2007.

VIGOTSKI, L. S. A tragédia de Hamlet, príncipe da Dinamarca. Tradução de Paulo Bezerra. São Paulo: Martins Fontes, 1999.

VIGOTSKI, L. S. Imaginação e criação na infância. São Paulo: Ática, 2009.

VIGOTSKI, L. S. Psicologia da Arte. Tradução Paulo Bezerra. São Paulo: Martins Fontes, 2001.

WEDEKIN, L. M. Psicologia e arte: os diálogos de Vigotski com a arte russa de seu tempo. Florianópolis, 2015. Dissertação (Mestrado em Psicologia) - Universidade Federal de Santa Catarina.

WEDEKIN, L. M.; ZANELLA, A. V. Arte e vida em Vigotski e o modernismo russo. Psicologia em Estudo, Maringá, v. 18, n. 4, p. 689-699, dez. 2013. https://doi.org/10.1590/S1413-73722013000400011. 